\title{
19 \\ CLIMATE CHANGE, \\ HEALTH AND WELL-BEING IN \\ INDIGENOUS AUSTRALIA
}

DONNA GREEN AND LEANNE WEBB

\section{Abstract}

The National Adaptation Research Plan for Human Health, the Intergovernmental Panel on Climate Change's Fourth Assessment Report and Garnaut's Climate Change Review all identify Indigenous Australians as disproportionately vulnerable to adverse health impacts from climate change. These statements are based on the reasonable assumption that significantly socio-economically disadvantaged people will have less capacity to adapt to anthropogenic climate change. There is, however, very limited quantitative analysis of this relationship that could be used to substantiate these claims. The two projects outlined in this chapter address this issue by detailing studies undertaken in Australia to investigate how climate impacts the morbidity and psychosocial health of Indigenous people. This research aims to provide decision makers with clear and robust policy-relevant evidence that identifies the connections between climate and the health and well-being of Indigenous people living in the tropical north of Australia.

\section{Introduction}

To readers of this volume, it would come as no surprise that Tony McMichael was always at the forefront of strategic research on the relationship between human health and climate. Our first experience of his leadership in this area came during a presentation he gave at a meeting of Indigenous Elders and scientists in 2006, where he discussed the indirect health impacts of climate change in northern Australia (McMichael, 2006). Five years later, he had further developed his model, presenting some novel dimensions at the International Congress of Biometeorology (McMichael, 2011). 


\section{Cultural and Psychosocial Health Dimensions of Climate Change}

One frequently overlooked area that Tony identified in this latter presentation was that of the 'community morale and mental health disorders' likely to be exacerbated through a number of complex mediated processes resulting from various climate impacts. Concern over this research area has been given much less attention than the more 'visible' (i.e. physical) impacts of climate change on human health, although the implications of these more insidious impacts have significant ramifications for at least one specific subpopulation in Australia (Baker et al., 2001; Hunter, 2009; Australian Institute of Health and Welfare (AIHW), 2011; Doherty and Clayton, 2011).

Indigenous people living in rural and remote Australia have close attachments to their country ${ }^{1}$ (Altman and Kerins, 2012). Despite the 'best' efforts of colonisation, the cultural link between Indigenous people and their country has, for large areas of the continent, remained strong (Carson et al., 2007; Campbell et al., 2011). What has been weakened by the work of missionaries and government intervention over the last two to three generations is the maintenance of their 'country' and, by inference, the cultural responsibility of 'looking after' their ancestors that comes with the practice of this 'people on country' interaction (Baker et al., 2001).

In the past two decades, the 'healthy country, healthy people' literature has pointed to the multiple co-benefits of strengthening the connections between people and place (Burgess et al., 2009; Biddle, 2011). If cultural practice is to be maintained properly, its transmission needs to occur on the country and from Traditional Owners to younger generations (Reid, 1992; Altman and Kerins, 2012).

In addition, when Traditional Owners are able to manage their country properly, by burning, hunting and performing ceremony, there is a significant psychological benefit (Rose, 1992, in Carson et al., 2007). That is to say, when the country has people looking after it, it is no longer considered 'wild' (Parry, 2007). For Indigenous Australians, 'wild' or unmanaged country, that which is overgrown and depopulated, is a source of shame or embarrassment for those who have a cultural obligation to look after it. This view of managing landscapes sits in sharp relief to the colonial perception of untouched 'wilderness' areas, where the very desolation of the landscape is itself a source of beauty.

1 'Country' is a term much preferred by Aboriginals to 'land'. Though much Aboriginal territory has been colonised, at least the most common word in English which expresses some of the values of that territory has been adapted, allowing a partial reclamation. 
Climate change is most likely to complicate this established relationship between people and place in a range of ways. Although Indigenous people have been living in a changing natural environment for thousands of years, these shifts have tended to be more gradual than the climate change impacts projected to occur in the next two to three generations (Parry, 2007; Galloway McLean, 2010). Indeed, some of these biophysical impacts on Indigenous managed land and sea country have already been documented: coastal areas have been threatened with more frequent and/or severe inundation (Green et al., 2010b), saltwater intrusion has occurred in wetland systems (Kakadu National Park, 2007; Green et al., 2009) and erosion of areas of special cultural significance have all been documented in the peer-reviewed literature, as well as via less traditional methods, such as video recordings (Ameyali, 2009).

Subtle impacts are occurring at the species level in response to climate change. For Indigenous communities that maintain cultural practices dependent on specific plants and animals, a change in flowering times, animal behaviour or species' ranges has important implications for their ability to hunt or harvest specific bush foods (Green et al., 2010a). Previously associated species' behaviours are being 'de-linked', so that, for example, the timing of hunting or foraging for a specific animal due to the visual cue of the behaviour of another animal, or the flowering of a specific plant, is being disrupted (Green et al., 2010a). When these processes are associated with cultural practice, a disruption in culture is a likely result - as has already been documented in other Indigenous communities around the world (see, for example, Turner and Clifton, 2009).

Within this context, we brought together a multidisciplinary team to carry out two distinct but related research projects to explore these issues further. Using different approaches appropriate to each research question, we wanted to explore both the quantitative and qualitative dimensions to this issue. The rest of this chapter outlines how we shaped these projects, and the preliminary results we have obtained.

\section{Qualitative Environmental Change and Health and Well-being Project}

The first research project takes a qualitative approach to explore how the health and well-being of an Indigenous community might be affected by climate impacts, and what strategies might best be engaged to build the community's resilience to these impacts. Specifically, this research examines connections between the health of Indigenous individuals and the health of their community, their culture and their country. 
To explore these possible psychosocial impacts of climate change on Indigenous Australians living in remote areas, we drew on the Indigenous research methods (IRM) approach (see Sherwood, 2010, for details on this process). This approach suggests that the research project be guided by the partner Indigenous community to establish their initial set of priorities and concerns for the research to respond to.

Another facet of this project is to show whether cultural practice and knowledge of their country still remain with these Elders. If this is the case, then it would be reasonable to design climate adaptation policies for this region that would encourage the return to living in and working on the country and the reinvestment in families returning to live for some of the year on outstations, where their connection to the country can continue to be strengthened. This research explores the proposition that taking people back on the country, and allowing the transfer of cultural knowledge between generations to occur, facilitates cultural resilience. With this mechanism to strengthen cultural practice, we test the hypothesis that resilience to environmental changes, such as those brought about by climate change, will also be strengthened.

Through developing a collaborative research partnership with Aak Puul Ngantam, an Aboriginal owned and run organisation based in Aurukun, on the west side of Cape York, Queensland, the project design was finalised and approved by its steering committee in 2012. The steering committee considered the research important to the community because of the need to factor climate adaptation strategies into their new economic development plan. It was also seen as an approach to strengthen their work on cultural resilience to make the community more sustainable by encouraging community members to take more trips out of Aurukun and back on to their traditional country.

This project was directed by the committee to work directly with Wik and Kugu Traditional Owners via the use of video recording, so that people could have a visual and audio record that they could keep for themselves and also use as a cultural record to enable material to be passed down to younger family members. This process follows the oral tradition of Indigenous societies, and the methods engaged in this project have international precedent (Willox et al., 2012). There was a clear direction from the steering committee that people wanted to return to their country in order to be able to speak about it, and so the logistics were organised to bring people out for short trips away from the Aurukun community to facilitate this process.

On the first trip, we worked with three Traditional Owners, who were taken out with an anthropologist who had worked with them in the mid-1970s and with whom they had spent a great deal of time. On each occasion, we worked in a different setting. With one artist, we spent time documenting the collection 
of traditional materials for weaving and painting. This recording occurred just outside of the main town area of Aurukun, and at the arts centre. The second recording took place at Waakacham, an area known for good geese hunting. To get to this location, we travelled by boat, and on the way, we discussed the environmental changes that this Elder observed along the riverbanks. We spent time discussing burning strategies and the damage caused to the country by feral pigs, while the rangers who had accompanied us went geese hunting. The final recording was taken of an Elder discussing his country and remembering, and singing, songs associated with it, although we were not able on that occasion to be able to travel to his country due to the overgrown state of the land between it and Aurukun. From these three recordings, it was clear that there remained a good level of knowledge about songs for these regions, and that the Elders were very keen on returning to their country to be able to carry out cultural activities there on future trips.

On the second trip, three Elders were again taken out with the anthropologist. This trip took people back to country near the Kendall River (see Figure 19.1), which they had not seen for years, including for one Elder, a trip back to the country where he had been born but had not visited since that time. The trip also allowed opportunities for people to remember times spent on the country when they were younger and events that had happened there, which was triggered by seeing specific plants, animals and features in the landscape. Some areas of the country were considered to have become overgrown and wild, and so were burned during our time working there. In other places, the Elders noted that there had been significant shifts in the landscape features, from changes in the composition of mangroves and trees, to the location of sandbanks and dunes. Feral pigs had also caused a great deal of environmental damage in many areas. Due to the overgrowth of weeds that had occurred in many of these regions, people had effectively been prevented from spending significant, if any, time back on their country. On this second trip, the use of a helicopter was essential, as we had to get over land that had roads which had become inaccessible or were non-existent (as people previously would have walked through these regions). The perspective from the air gave the Elders an opportunity to see how various places had become overgrown, the damage that had been caused by feral animals and which areas of the land were in need of being burned. 


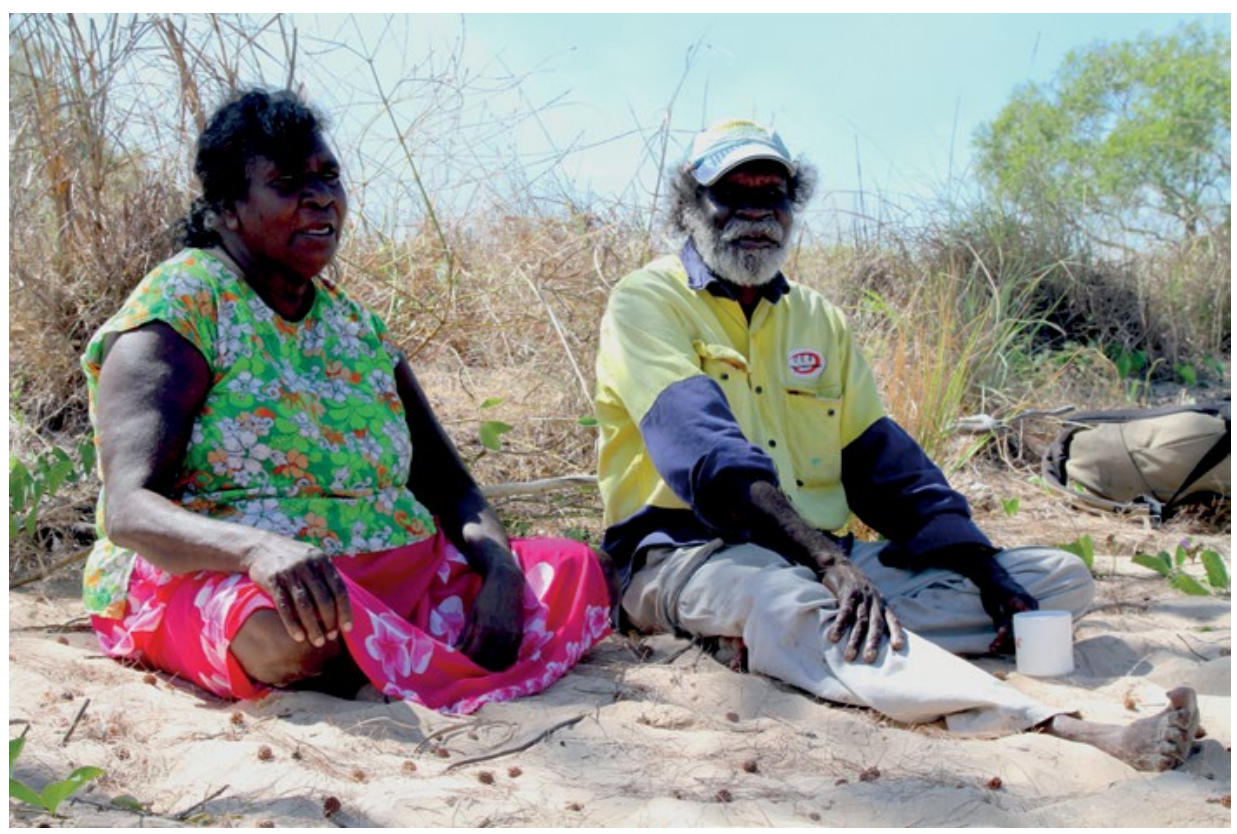

\section{Figure 19.1 Mavis Ngallametta and Stuart Korkaktain discussing the management of their country, Kendal River, Cape York.}

Source: Donna Green.

Over eight hours of material was recorded from these trips. Much of this material documents Traditional Owners' experiences in going back to their country, and their thoughts and feelings about how it has changed since their last visit. It records songs connected to place, and cultural activities carried out there. From these recordings, we will spend time working with the Elders to explore how people's perceptions of ecosystems have changed. This approach is taken in order to understand better what environmental change is likely to cause distress, and therefore what activities might be considered important to mitigate this problem.

These two trips back to country were considered a great success, with people keen to return to their land for a longer period during the following dry season, and to bring some of their children with them so that specific cultural knowledge could be transmitted to the younger generation. This return trip was carried out in the dry season of 2013, and the researchers collaborated with the school in order that some of this cultural transmission work could be incorporated into the children's activities.

Other potential benefits from this research work were identified by the collaboration. For example, the new federal climate change policy could provide employment opportunities to reconnect Elders with their land via burning 
and feral animal management programmes. Ranger programmes are now providing real employment opportunities over thousands of hectares, and these programmes must operate under the direction of Traditional Owners to ensure that the correct protocols are followed to burn and manage country (Green and Minchin, 2012). One relatively new initiative is that of carbon management; that is, the controlled burning of dry land savannah in mosaic patterns in the cooler earlier months. In this way, less carbon dioxide is emitted through uncontrolled late-season burns, which have a much greater fuel load available to them (Barnsley, 2008). Through projects such as this, it is anticipated that Australia's greenhouse gas emissions can be reduced (Parry, 2007). A carbon management project that would fit within this federal climate change policy is currently under consideration by the Elders of this community.

\section{Quantitative Health and Climate Project}

The quantitative dimension of this work was carried out in a separate research project. This project was designed to investigate whether we could establish a climate-health link that might have disproportionate impacts on Indigenous Australians (Webb et al., 2014). We used epidemiological methods to analyse observed admission rates for cardiovascular disease over a 20-year period (1992-2011) from the five public hospitals in the Northern Territory. Admissions made on very hot, very cold and 'other' days were quantified. These days are defined as the fifth and 95th percentile of observed maximum temperature $\left(\operatorname{Tmax}{ }^{\circ} \mathrm{C}\right)$, minimum temperature $\left(\operatorname{Tmin}{ }^{\circ} \mathrm{C}\right)$ and wet bulb globe temperature (WBGT ${ }^{\circ} \mathrm{C}$ ) (Steadman, 1994). Results were assessed separately for the Indigenous and the non-Indigenous community, younger and older age groups and males and females.

The rationale behind this assessment relates to the fact that, on most measures of health, Indigenous Australians fare much worse than non-Indigenous Australians, including experiencing significantly higher rates of chronic diseases and hospitalisations (Pink and Allbon, 2008) and lower life expectancy (Hill et al., 2007). Despite this, an investigation as to whether there could be a connection between the rates of hospitalisations of Indigenous Australians for specific diseases and the climate in which they live has not occurred.

Because the study population is spread over a very large area, and influenced by greatly varying climatic conditions, it was necessary to break the admissions data into similar 'exposure' groups by aligning the residence data with the closest weather station (see Webb et al., 2014, for a detailed description of the method employed to create the subregions in the study). 
The analysis focused on cardiovascular disease, the largest contributor to the disparity in the health of Indigenous and non-Indigenous people (Penm, 2008). Further, the association between cardiovascular disease and environmental conditions has already been established for some regions in Australia (Khalaj et al., 2010; Loughnan et al., 2008, 2010a, 2010b).

Two of the more common cardiovascular diseases were studied. Ischaemic heart disease (IHD) (ICD9 410-414, ICD10 I20-I25) is the major cardiovascular disease diagnosis in the Northern Territory region (Pink and Allbon, 2008) and is characterised by a reduced blood supply to the heart muscle. Symptoms of IHD include angina, characteristic chest pain on exertion and decreased exercise tolerance. Heart failure (ICD9 428, ICD10 I50), the other disease studied, occurs where the heart is unable to provide sufficient pump action to maintain blood flow to meet the body's requirements (McMurray and Pfeffer, 2005). Heart failure is 1.7 times more prevalent in Indigenous compared to non-Indigenous Australians (Penm, 2008).

It is interesting to note the different rates for the various cohorts, showing that the major disparity in admission rates is found in the younger population (25 to 64 years), with the contrast in the admission rate for the older group less striking. In fact, older non-Indigenous males have higher rates of admission than their Indigenous counterparts (Webb et al., 2014). Notably, for most of the study groupings, males are admitted at higher rates than females.

The sensitivity in daily admissions data to climatic 'extremes' varied by disease group, age category and sex. These are described by 'rate ratios'. Rate ratios are rates for 'very hot' and 'very cold' periods divided by the rates for the 'non-extreme' periods, with numbers greater than one associated with increased rates and numbers less than one with decreased rates.

In the 25- to 64-year-old cohort, a significant 17 per cent increase in admission rates for IHD was detected in the Indigenous population on very hot days. In particular, Indigenous females $(32$ per cent increase, $P<0.05)$ were most affected by higher maximum temperatures. No strong temperature response was noted for heart failure admissions in the younger group. We proposed ambient heat would not be a direct cause of the increased rates of IHD in the Indigenous females, but would increase physiological stress and, given other pre-existing health issues, the heat impact would be compounded.

We found a contrasting response to climatic conditions compared with the younger group. In general, for older people, an increased rate of admissions was observed in response to cold conditions, with a reduction in admissions on very hot days. The most notable increase was found in the older male population. This tendency was also apparent for females being admitted for heart failure. 
This finding is consistent with other studies showing the positive influence of cold temperatures on rates of admission for heart conditions (McGregor, 2001; Abrignani et al., 2009).

In cold conditions, the primary autonomic defences are vasoconstriction and shivering (Sessler, 2009). The cold sensitivity response derives from a combination of cardiorespiratory response, blood clotting, renal and immune effects. These increase heart rate and blood pressure, while reducing cardiac muscle contractility, deplete blood volume and increase blood viscosity (Keatinge et al., 1984; Pozos and Danzl, 2001). Cold conditions may have a stronger influence on increasing morbidity associated with heart failure, compared to IHD, because of the extra effort for the heart to pump around more viscous, higher-pressure blood. It is interesting to note that in the older population, on hotter days there is a tendency towards lower admissions for heart failure.

This epidemiological assessment indicates that projected climate change may exacerbate recently documented disparities in cardiovascular disease outcomes for Indigenous and non-Indigenous populations (Vos et al., 2009). This is because an increase in the frequency of hot days and a decrease in the frequency of cold days, as projected (Alexander and Arblaster, 2009), will possibly cause increased admissions for IHD in younger Indigenous people and reduced admissions in older populations.

Overall, rates of hospitalisation were found to be higher for older people compared to younger people, Indigenous people compared to non-Indigenous people and males compared to females. In general, the younger (25 to 64 years) Indigenous population has a tendency to higher rates of admissions on very hot days and the older $(65+)$ non-Indigenous male population have higher rates of admission on very cold days.

In the absence of adaptation activities, this analysis suggests that climate change is likely to have greater adverse health effects - at least for cardiovascular-related events - in the Indigenous compared to non-Indigenous population, with the increase in heat-related admissions in the younger population most likely to outweigh the reduction to rates of admission in older Indigenous people, especially from a burden of disease perspective.

From this work to date, our initial conclusions are that increasingly disproportionate impacts on the health of the Indigenous population living in the Northern Territory may result from projected climate changes. Further analysis on other non-communicable diseases and climate thresholds will be assessed prior to making broader policy recommendations. Due to the success of this investigation into cardiovascular responses to climate, the next phase of this research will investigate whether there is also a link between respiratory admissions and climate. 


\section{References}

Abrignani, M.G., Corrao, S., Biondo, G.B., Renda, N., Braschi, A., Novo, G., et al. 2009. Influence of climatic variables on acute myocardial infarction hospital admissions. International Journal of Cardiology 137(2), 123-9.

Alexander, L.V. \& Arblaster, J.M. 2009. Assessing trends in observed and modelled climate extremes over Australia in relation to future projections. International Journal of Climatology 29, 417-35.

Altman, J. \& Kerins, S. 2012. People on Country, Vital Landscapes, Indigenous Futures. The Federation Press, Canberra, ACT, Australia.

Ameyali, R. 2009. Sea level rise in Kowanyama. Available at: ourworld.unu.edu/ en/sea-level-rise-in-kowanyama, accessed 27 January 2015.

Australian Institute of Health and Welfare (AIHW) 2011. Australia's Welfare 2011. AIHW, Canberra, Australia.

Baker, R., Davies, J. \& Young, E. 2001. Working on Country: Contemporary Indigenous Management of Australia's Lands and Coastal Regions. Oxford University Press, Oxford, UK.

Barnsley, I. 2008. Emissions Trading, Carbon Financing and Indigenous Peoples. UNU-IAS, Japan.

Biddle, N. 2011. Measures of Indigenous wellbeing and their determinants across the lifecourse. CAEPR Lecture series. The Australian National University, Canberra, ACT, Australia.

Burgess, C., Johnston, F., Berry, H., McDonnell, J., Yibarbuk, D., Gunabarra, C., et al. 2009. Healthy country, healthy people: the relationship between Indigenous health status and 'caring for country'. Medical Journal of Australia 190, 567-72.

Campbell, D., Burgess, C., Garnett, S. \& Wakerman, J. 2011. Potential primary health care savings for chronic disease care associated with Australian Aboriginal involvement in land management. Health Policy 99, 83-9.

Carson, B., Dunbar, T., Chenhall, R. \& Bailie, R. (eds) 2007. Social Determinants of Indigenous Health. Allen and Unwin, Sydney, NSW, Australia.

Doherty, T. \& Clayton, S. 2011. The psychological impacts of global climate change. American Psychologist 66 (4), 265-76. 
Galloway McLean, K. 2010. Advance Guard: Climate Change Impacts, Adaptation, Mitigation and Indigenous Peoples. Australia, United Nations University Traditional Knowledge Initiative, Darwin, NT, Australia.

Green, D. \& Minchin, L. 2012. The co-benefits of carbon management on country. Nature Climate Change 2, 641-3.

Green, D., Jackson, S. \& Morrison, J. 2009. Risks from Climate Change to Indigenous Communities in the Tropical North of Australia. Department of Climate Change, Canberra, ACT, Australia.

Green, D., Alexander, L., Mclnnes, K., Church, J., Nicholls, N. \& White, N. 2010a. An assessment of climate change impacts and adaptation for the Torres Strait Islands, Australia. Climatic Change 102, 405-33.

Green, D., Billy, J. \& Tapim, A. 2010b. Indigenous Australians' knowledge of weather and climate. Climatic Change 100, 337-54.

Hill, K., Barker, B. \& Vos, T. 2007. Excess Indigenous mortality: are Indigenous Australians more severely disadvantaged than other Indigenous populations? International Journal of Epidemiology 36, 580-9.

Hunter, E. 2009. 'Radical hope' and rain: climate change and the mental health of Indigenous residents of northern Australia. Australasian Psychiatry 17, $445-52$.

Kakadu National Park 2007. Management Plan 2007-2014. Board of Management (Director of National Parks, Northern Territory), Kakadu, NT, Australia.

Keatinge, W., Coleshaw, S., Cotter, F., Mattock, M., Murphy, M. \& Chelliah, R. 1984. Increases in platelet and red cell counts, blood viscosity, and arterial pressure during mild surface cooling: factors in mortality from coronary and cerebral thrombosis in winter. BMJ 289, 1405-8.

Khalaj, B., Lloyd, G., Sheppeard, V. \& Dear, K. 2010. The health impacts of heat waves in five regions of New South Wales, Australia: a case-only analysis. International Archives of Occupational and Environmental Health 83, 833-42.

Loughnan, M., Nicholls, N. \& Tapper, N. 2008. Demographic, seasonal, and spatial differences in acute myocardial infarction admissions to hospital in Melbourne Australia. International Journal of Health Geographics 7, 42 doi:10.1186/1476-072X-7-42. 
Loughnan, M.E., Nicholls, N. \& Tapper, N.J. 2010a. The effects of summer temperature, age and socioeconomic circumstance on Acute Myocardial Infarction admissions in Melbourne, Australia. International Journal of Health Geographics 9, 41. www.ij-healthgeographics.com/content/9/1/41.

Loughnan, M.E., Nicholls, N. \& Tapper, N.J. 2010b. When the heat is on: threshold temperatures for AMI admissions to hospital in Melbourne Australia. Applied Geography 30 (1), 63-9.

McGregor, G. 2001. The meteorological sensitivity of ischaemic heart disease mortality events in Birmingham, UK. International Journal of Biometeorology $45,133-42$.

McMichael, A.J. 2006. Climate change and risks to health in remote Indigenous communities. Sharing Knowledge: A Workshop on Climate Change Impacts and Adaptation Strategies for Northern Australian Indigenous Communities. Darwin, Australia. Available at: www.sharingknowledge.net.au, accessed 27 January 2015.

McMichael, A.J. 2011. Climate and health (Keynote address). 19th International Congress of Biometeorology, Auckland, New Zealand.

McMurray, J.J.V. \& Pfeffer, M.A. 2005. Heart failure. The Lancet 365, 1877-89.

Parry, M.L. (ed.) 2007. Climate Change 2007: Impacts, Adaptation and Vulnerability: Working Group I Contribution to the Fourth Assessment Report of the IPCC. Cambridge University Press, Cambridge, UK.

Penm, E. 2008. Cardiovascular disease and its associated risk factors in Aboriginal and Torres Strait Islander peoples 2004-05. Cardiovascular Disease Series No. 29. AIHW, Canberra, ACT, Australia.

Pink, B. \& Allbon, P. 2008. The Health and Welfare of Australia's Aboriginal and Torres Strait Islander Peoples. Australian Bureau of Statistics, Australian Institute of Health and Welfare, Canberra, ACT, Australia.

Pozos, R.S. \& Danzl, D. 2001. Human physiological responses to cold stress and hypothermia. In: Pandoff, P. \& Burr, M. (eds) Medical Aspects of Harsh Environments Vol 1. Department of the Army, Washington, DC, USA, 351-82.

Reid, J. 1992. Body, Land and Spirit: Health and Healing in Aboriginal Society. University Queensland Press, Brisbane, QLD, Australia.

Rose, D. (ed.) 1992. Dingo Makes Us Human: Life and Land in an Australian Aboriginal Culture. Cambridge University Press, Cambridge, UK. 
Sessler, D.I. 2009. Thermoregulatory defense mechanisms. Critical Care Medicine 37, S203-S210.

Sherwood, J. 2010. Do No Harm: Decolonising Aboriginal Health Research. PhD thesis, University of New South Wales, Sydney, NSW, Australia.

Steadman, R.G. 1994. Norms of apparent temperature in Australia. Australian Meteorological Magazine 43, 1-16.

Turner, N. \& Clifton, H. 2009. 'It's so different today': climate change and Indigenous lifeways in British Columbia, Canada. Global Environmental Change 19, 180-90.

Vos, T., Barker, B., Begg, S., Stanley, L. \& Lopez, A.D. 2009. Burden of disease and injury in Aboriginal and Torres Strait Islander peoples: the Indigenous health gap. International Journal of Epidemiology 38, 470-7.

Webb, L., Bambrick, H., Tait, P., Green, D. \& Alexander, L. 2013. Effect of ambient temperature on Australian Northern Territory public hospital admissions for cardiovascular disease among Indigenous and non-Indigenous populations. International Journal of Environmental Research and Public Health, 11 (2), 1942-59.

Willox, A., Harper, S. \& Edge, V. 2012. Storytelling in a digital age: digital storytelling as an emerging narrative method for preserving and promoting indigenous oral wisdom. Qualitative Research 13, 127-47. 
This text is taken from Health of People, Places And Planet:

Reflections based on Tony McMichael's four decades of contribution to epidemiological understanding, edited by Colin D. Butler, Jane Dixon and Anthony G. Capon, published 2015 by ANU Press, The Australian National University, Canberra, Australia. 